\title{
One size doesn't fit all: the influence of supervisors' power tactics and subordinates' need for cognitive closure on burnout and stress
}

Jocelyn J. Bélanger, Antonio Pierro, Barbara Barbieri, Nicola A. De Carlo, Alessandra Falco \& Arie W. Kruglanski

To cite this article: Jocelyn J. Bélanger, Antonio Pierro, Barbara Barbieri, Nicola A. De Carlo, Alessandra Falco \& Arie W. Kruglanski (2015): One size doesn't fit all: the influence of supervisors' power tactics and subordinates' need for cognitive closure on burnout and stress, European Journal of Work and Organizational Psychology, DOI: 10.1080/1359432X.2015.1061999

To link to this article: http://dx.doi.org/10.1080/1359432X.2015.1061999

\section{曲 Published online: 25 Jun 2015.}

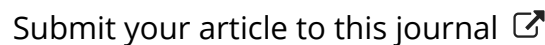

山 Article views: 38

Q View related articles ¿

View Crossmark data $\asymp$ 


\title{
One size doesn't fit all: the influence of supervisors' power tactics and subordinates' need for cognitive closure on burnout and stress
}

\author{
Jocelyn J. Bélanger $^{\mathrm{a} *}$, Antonio Pierro ${ }^{\mathrm{b}}$, Barbara Barbieri ${ }^{\mathrm{b}}$, Nicola A. De Carlo ${ }^{\mathrm{c}}$, Alessandra Falco ${ }^{\mathrm{c}}$ and Arie W. Kruglanski ${ }^{\mathrm{d}}$ \\ ${ }^{a}$ Département de Psychologie, Université du Québec à Montréal, Montreal, Canada; ${ }^{b}$ Dipartimento di Psicologia, University of Rome \\ "La Sapienza", Rome, Italy; ${ }^{c}$ Department of General Psychology, University of Padua, Padua, Italy; ${ }^{d}$ Department of Psychology, \\ University of Maryland, College Park, Maryland, USA
}

(Received 17 February 2014; accepted 10 June 2015)

\begin{abstract}
The present research investigated the notion of fit between supervisors' power tactics and subordinates' need for cognitive closure (NFCC) on subordinates' burnout and stress. Subordinates who tend to avoid ambiguity (high NFCC) were expected to experience relatively less burnout (Study 1) and stress (Study 2) if their supervisors utilize harsh (controlling and unequivocal) power tactics and more burnout and stress if their supervisors utilize soft (autonomy-supportive and equivocal) power tactics. In contrast, it was expected that subordinates who avoid firm and binding conclusions (low NFCC) would experience relatively less burnout and stress if their supervisors use soft power tactics and more burnout and stress if they use harsh power tactics. Two studies conducted in diverse organizational settings supported these hypotheses. Collectively, these results support the conclusion that soft (vs. harsh) power tactics are not always associated with better (vs. worse) organizational outcomes. Theoretical and practical implications for organizations are discussed.
\end{abstract}

Keywords: burnout; stress; power; need for cognitive closure

Experiencing stress at work is a common symptom plaguing workers' daily lives. Stress refers to an unpleasant emotional experience associated with fear, anxiety, and emotional exhaustion (EE) (Lazarus \& Folkman, 1984; Sonnentag, 2005). According to the World Health Organization (2003), stress is one of the primary sources of depression and burnout, a billion dollar problem draining organizational profit by increasing turnover rates (Gupta \& Beehr, 1979) and absenteeism (Karasek, 1979). Interestingly, among the plethora of possible stressors in organizational settings, one of the leading causes of stress relates to supervisor-subordinate relationships (Landeweerd \& Boumans, 1994; Tepper, 2000). In that regard, mounting evidence suggests that many stressrelated symptoms at work arise when supervisor-subordinate relationships are perceived as psychologically unhealthy (Cooper \& Payne, 1991; Skakon, Nielsen, Borg, \& Guzman, 2010).

As one can imagine, relationships come in different shapes and sizes and a great deal of variability exists in what creates a "healthy relationship". One characteristic that may promote good supervisor-subordinate interactions is the strategies supervisors utilize to gain compliance from their subordinates. Indeed, there is precedent in the industrial-organizational literature suggesting that autonomy-supportive, or soft, power tactics (as opposed to controlling, or harsh, power tactics) not only are preferred by subordinates, but also tend to yield more positive subordinate-outcomes such as greater job satisfaction, organizational commitment, and quality interactions with supervisors (Gupta \& Sharma, 2008; Koslowsky, Schwarzwald, \& Ashuri, 2001; Pierro, Raven, Amato, \& Bélanger, 2013). With regard to stress, research indicates that soft and harsh power tactics are, respectively, negatively and positively, associated with subordinates' stress at work (Erkutlu, Chafra, \& Bumin, 2011). Collectively, the current research on social power unanimously recognizes that to enhance subordinates' motivation, collegiality, and well-being, supervisors should opt for soft power tactics and refrain from using harsh ones, thereby prescribing a "one size fits all" approach to management.

Counter to this line of thought, Pierro, Kruglanski, and Raven (2012) have recently proposed that not all subordinates may necessarily respond positively to soft (or negatively to harsh) power tactics. Drawing on the PersonEnvironment (P-E) fit theory (Kristof-Brown, Zimmerman, \& Johnson, 2005), they postulated that subordinates' need for cognitive closure (NFCC) (P), which reflects a preference for unambiguity and certainty (Kruglanski, 2004), modulates how subordinates respond

\footnotetext{
*Corresponding author. Email: jocelyn.belanger@gmail.com 
to their supervisors' power tactics (E). Specifically, given that soft (vs. harsh) power tactics provide malleable and equivocal guidelines (vs. direct and unequivocal) for the work that needs to be done, those that seek clear rules and certainty (high NFCC) may be impacted negatively by such power tactics in comparison to those that avoid firm conclusions and like to keep their options opened (low NFCC). Supporting these predictions, Pierro and colleagues (2012) adduced evidence that supervisors' power tactics on subordinates' performance were moderated by subordinates' NFCC. As predicted, subordinates high (vs. low) on the need for closure displayed greater performance when their supervisors utilize harsh (vs. soft) power tactics, whereas subordinates low (vs. high) on the need for closure displayed greater performance when supervisors utilize soft (vs. harsh) power tactics.

This raises the question of whether the presence of fit between supervisors' power tactics and subordinates' need for closure could also influence subordinates' occupational well-being. Although prior research has found that supervisor-subordinate fit promotes better organizational performance, at this juncture, the influence of fit on subordinates' stress and burnout remains unclear. On the one hand, supervisor-subordinate fit may promote greater well-being because supervisors' power tactics address their subordinates' need for certainty. On the other hand, the beneficial effect of fit on performance shown in the work of Pierro et al. (2012) could also entail lower levels of well-being as theoretical models of performance have postulated and found that (up to a certain point) the presence of stress is necessary for performance (e.g., Harvey, Hammond, Lusk, \& Mross, 1992; Yerkes \& Dodson, 1908). Relatedly, social psychological research has documented that performance can be propelled by ego-threat and fear of failure (e.g., Bélanger et al., 2013a; Peters, Greenberg, Williams, Schneider, 2005), both of which are negatively related to life satisfaction and well-being (e.g., Elliot \& Sheldon, 1997; Hayes \& Weathington, 2007).

The aim of the present work was thus to empirically scrutinize a critical question for managers and subordinates: whether soft power tactics univocally promote wellbeing, as underscored in the work of Erkutlu et al. (2011), or whether subordinates' well-being is guided by more complex dynamics, as the work of Pierro et al. (2012) on supervisor-subordinate fit suggests. If supervisor-subordinate fit is related to greater occupational well-being, one major contribution of this work is that the long-held assumption that soft power tactics promote better organizational outcomes across-the-board should be revised. Similarly, there could be benefits in using harsh power tactics on some subordinates; therefore supervisors should not automatically refrain from using these power tactics. A third potential contribution would be that instead of relying on a "one size fits all" approach, supervisors looking after their subordinates' well-being should consider adapting their power tactics to their subordinates' tolerance for ambiguity and uncertainty (i.e., need for closure).

The research herein described examined the influence of supervisor-subordinate fit on subordinates' burnout (Study 1) and stress (Study 2), in different organizational settings. In what follows, we first briefly review the social power theory (Raven, Schwarzwald, \& Koslowsky, 1998) and then carry out a similar review for NFCC (Kruglanski \& Webster, 1996). Drawing on these notions, we then formulate our specific hypotheses and describe empirical studies designed to test them in order to point out ways in which organizations can improve subordinates' psychological well-being.

\section{Social power}

Social power is defined as the ability of an influencing agent to alter other people's beliefs, attitudes, and behaviour. The magnitude of this ability depends on the agent's available resources to produce such change (Cartwright, 1965; French \& Raven, 1959). An influential theoretical framework of social power was described by French and Raven (1959; see also Raven, 1965; Raven \& Kruglanski, 1970) to understand supervisors-subordinates interactions in organizational settings (e.g., Hinkin \& Schriesheim, 1990; Schwarzwald, Koslowsky, \& Agassi, 2001; Yukl \& Falbe, 1991). These authors distinguished six distinct bases of social power (or power tactics): (1) referent; (2) expert; (3) informational; (4) legitimate; (5) reward; and (6) coercive powers. More recently, the Interpersonal Power Interaction Model (IPIM, Raven, 2001，2008; Raven et al., 1998) further distinguished these bases of social power into 11 power tactics. These are described below.

(1) Expert power is derived from people's belief that one is knowledgeable in a given domain. Rather than reflecting genuine erudition, it is the perception of expertise that provides one with power; (2) in contrast, informational power is the ability of using information to provide logical arguments to persuade others; (3) referent power is predicated on one's ability to be liked, respected, and admired by others; (4) legitimate power of dependence, sometimes called the "power of the powerless", stems from the social responsibility norm, which puts pressure on people to assist others in need and/or those who are dependent upon them (Berkowitz \& Daniels, 1963); (5) reciprocity power is based on a social norm of returning favours to those that offered them (tit-for-tat; see Cialdini, 1993; Gouldner, 1960), whereas (6) legitimacy of position (see also Etzioni, 1961) refers to a social norm of obedience to one's superior. Another form of power is (7) legitimacy based on the equity norm (Walster, Walster, \& Berscheid, 1978), whereby individuals feel obligated to compensate others who either suffered a lot, worked hard, or were harmed in some ways.

The IPIM model includes four other types of power, namely coercion and reward that can be either personal or 
impersonal. (8) Personal coercion and (9) personal reward are at play when subordinates believe that compliance will result in being personally liked or disliked by the person in power (e.g., supervisor). On the other hand, (10) impersonal coercion and (11) impersonal reward refer to threats of punishment or promises of reward based on compliance (e.g., demotions or promotions).

In prior research, the 11 power tactics described under the IPIM framework have been clustered into "soft" and "harsh" categories of social power (e.g., Pierro et al., 2013; Raven et al., 1998). Essentially, the harsh-soft dichotomy reflects the amount of freedom the target of influence has in choosing whether or not to comply with a request from a power figure. Specifically, harsh power tactics emphasize the supervisors' ability to reinforce or reprimand its subordinates, whereas soft power tactics emphasize supervisors' interpersonal influence, charisma, and mutual dependency (Raven et al., 1998; Schwarzwald, Koslowsky, \& Brody-Shamir, 2006). In the same vein, Erchul and colleagues (Erchul, Raven, \& Whichard, 2001) posited that "soft (weak) bases tend to be more subtle, positive, and noncoercive; hard (harsh) bases tend to be more overt, punitive, and heavy-handed" (p. 487). In keeping with this perspective, personal and impersonal coercion/reward, legitimacy of position, equity, and reciprocity ${ }^{1}$ have been associated with harsh power tactics because compliance is based on enforceable rules and is encouraged by negative or positive consequences contingent on compliance. In contrast, expert, referent, informational power, and legitimacy of dependence have been grouped under soft power tactics because no enforceable rules dictate the dispensation of rewards/punishments and individuals feel free to decide whether or not to comply with a given request. Consistent with the theoretical postulates of the IPIM, factor analyses have yielded results supporting the harsh-soft distinction (Pierro et al., 2013; Raven et al., 1998; Schwarzwald et al., 2001).

Mounting evidence suggests that supervisors' power tactics have wide-ranging implications for their subordinates. For instance, in diverse organizational settings, Gupta and Sharma (2008) demonstrated that soft power tactics are positively correlated with being satisfied with one's superior, whereas harsh power tactics were unrelated to it. Soft power tactics are also positively related to affective organizational commitment-the attachment of an individual to his or her organization-no such correlation was found with harsh power tactics (Pierro et al., 2013). In a sample of nurses, Koslowsky and colleagues (2001) demonstrated that soft and harsh power tactics were both positively correlated with subordinates' job satisfaction. However, the correlation coefficient for soft power tactics $(r=.36)$ was much stronger than for harsh power tactics $(r=.15)$. With regard to occupational wellbeing, research by Erkutlu and colleagues (2011) evinced that soft and harsh power tactics are, respectively, negatively and positively associated with subordinates' stress. These relationships were found to be stronger when the organizational culture fosters respect for people, and weaker when it encourages competitiveness, thus supporting the view that respectful (vs. competitive) environments increase the importance of interpersonal relationships (vs. distribution of rewards) on which soft (vs. harsh) power tactics hinge on. Collectively, the current social power literature suggests that managers should opt for soft (vs. harsh) power tactics to obtain better organizational outcomes.

The IPIM also delineates personality, motivational, and situational variables expected to affect power tactics chosen by the influencing agent and the target's decision to comply. Situational factors include social norms, work setting, organizational culture, and organizational position (e.g., Koslowsky \& Schwarzwald, 2001; Pierro \& Raven, 2006; Raven, 1992, 1993; Schwarzwald, Koslowsky, \& Ochana-Levin, 2004). Personality and motivational factors relevant to the choice of power tactics or the decision to comply include self-esteem, needs for power, affiliation, achievement, independence, intrinsic-extrinsic motivational orientations, desire for control, and self-presentational styles (for a review see Pierro, Cicero, \& Raven, 2008; Raven, 2004). Another motivational factor that relates to power tactics is subordinates' NFCC. In the following section we introduce the NFCC construct and discuss its relevance to the topic of social power and stress.

\section{Need for cognitive closure}

NFCC is a motivational construct that pertains to individuals' "desire for a firm answer to a question, any firm answer as compared to confusion and/or ambiguity ${ }^{2}$, (Kruglanski, 2004, p. 6). NFCC has been demonstrated to have bearing on people's decision-making process (Kruglanski, 2004; Kruglanski \& Webster, 1996) and the kind of groups people form and find congenial (Kruglanski, Pierro, Mannetti, \& De Grada, 2006). Some individuals are compelled to avoid cognitive closure, whereas others may try to obtain it. Research has shown that people's standing on the NFCC continuum is determined by the perceived costs and benefits of having versus lacking closure (Webster \& Kruglanski, 1994). Such costs and benefits can be made salient by several contextual features such as time pressure, boredom, noise, and fatigue (for a review see Kruglanski, 2004).

When individuals have a strong NFCC, they urgently seek information promising to reduce ambiguity in a permanent way. It has been theorized and empirically shown that individuals with a strong NFCC tend to "seize" on information permitting a judgment on a topic of interest, and to "freeze" upon such judgment, becoming relatively "closed-minded" to further relevant information 
(Kruglanski, Webster, \& Klem, 1993). Thus, individuals with high levels of NFCC make strong judgmental commitments, are relatively unshaken in their views, and do not cope well with change (Kruglanski, Pierro, Higgins, \& Capozza, 2007). In contrast, individuals with a strong need to avoid closure are leery of judgmental commitments; they feel more comfortable keeping their options opened, eschewing binding views or definite opinions (Kruglanski \& Webster, 1996).

In the last few decades, research has supported the notion that NFCC permeates human affairs by affecting a variety of intrapersonal, interpersonal, and group phenomena (see Kruglanski, 2004 for a review). Because it fosters a desire for stable knowledge (Kruglanski \& Webster, 1996), NFCC induces a quest for consensus or "shared reality" among group members (Kruglanski et al., 2006). Accordingly, it was found that groups composed of dispositionally high (vs. low) NFCC members exerted and experienced greater uniformity pressures (De Grada, Kruglanski, Mannetti, \& Pierro, 1999), adhere to situational norms (Kruglanski et al., 2006), reported a stronger desire to agree with other group members (Kruglanski et al., 1993), exhibited a tendency to reject opinion deviations (Kruglanski \& Webster, 1991), and preferred homogenous groups (Kruglanski, Shah, Pierro, \& Mannetti, 2002). In a similar vein, NFCC has been associated with political conservatism (Jost, Glaser, Kruglanski, \& Sulloway, 2003) and group norms stability across varying generations of membership (Livi et al., 2007).

Research on group dynamics by Pierro et al. (Pierro, Mannetti, De Grada, Livi, Kruglanski, 2003) has also measured and experimentally manipulated NFCC via time pressure. Their results evinced that groups composed of dispositionally high (vs. low) NFCC members promote the emergence of autocratic (i.e., hierarchical) group structures. In these groups, one member tends to become the "hub of the group" by controlling the discussion floor, which results in significant influence gain for that person over other in-group members. Pierro and colleagues (2003) posited that the formation of leaders whose pronounced opinions "betokens the "end of discussion" (p. 415) serves as a means to gain closure more rapidly than egalitarian groups. In line with this perspective, Pierro, Cicero, Bonaiuto, Van Knippenberg, and Kruglanski (2005) have examined the effectiveness of prototypical leaders on several employees' work-related outcomes. Prototypical leaders are group members that act as social reality providers by symbolizing what in-group members share through the embodiment of the group's normative behavioural prescriptions (Hogg \& Reid, 2001; Turner, 2005). They tend to be more effective leaders than nonprototypical leaders because they have more influence and thus elicit greater conformity (Hogg, 1992; van Knippenberg, Lossie, \& Wilke, 1994). Pierro et al. (2005) hypothesized and found that the influence of leaders' prototypicality was moderated by subordinates' NFCC. Specifically, employees with a strong NFCC perceived prototypical leaders as more effective while displaying greater job satisfaction, greater performance, and less turnover intentions.

In summary, mounting evidence supports the notion that a heightened NFCC induces a quest for decisive knowledge, consensus, and a preference for strongly shared social realities (reflecting "seizing"), as well as the tendency to preserve such realities across varying conditions ("freezing").

\section{The present research}

According to the P-E fit theory (for a review see Judge \& Ferris, 1992; Kristof-Brown et al., 2005; Schneider, Goldstiein, \& Smith, 1995), fit is said to occur when a person or organization "supplements, embellishes, or possesses characteristics which are similar to other individuals" (Muchinsky \& Monahan, 1987, p. 269). In line with this theoretical framework, Pierro et al. (2012) have evinced that the notion of fit between subordinates' motivational orientation for closure (person) and supervisors' power tactics (environment) is important for subordinates' work performance. The goal of the present research was to examine whether these findings could be extended to subordinates' psychological well-being. Specifically, given that soft (vs. harsh) power tactics provide malleable and equivocal guidelines (vs. direct and unequivocal) for the work that needs to be done, those that seek clear rules and certainty (high NFCC) may experience less well-being compared to those that avoid firm conclusions and like to keep their options opened (low NFCC). If this is the case, then this would run counter to the idea that "one kind of power tactic fits all" and that soft power tactics (as opposed to harsh ones) are necessarily the most adapted power tactics to promote better psychological well-being (Erkutlu et al., 2011).

In this research, we examined two different criteria of well-being: stress and burnout. According to Lazarus (1966), stress arises when individuals perceive that they cannot adequately cope with the demands being made on or with threats to their well-being. Burnout, on the other hand, has been defined by Maslach and colleagues (1996) as "a syndrome of emotional exhaustion, depersonalization and reduced person accomplishment" (p. 4). Burnout is generally understood as the result of prolonged jobrelated stress, whereas stress can be episodic and shortlived (Hobfoll \& Shirom, 2000).

Despite being two adverse responses to stressors, burnout and stress have been posed as two distinct constructs (Caton, Grossnickle, Cope, Long, \& Mitchell, 1988). Research by Pines and Keinan (2005), for example, has shown that stress and burnout have different antecedents, correlates, and consequences. Specifically, their 
research indicated that 1) work stressors (conceptualized as antecedent variables) were more strongly related to stress than burnout; 2) burnout was more negatively related to work importance than stress (correlates), and 3 ) burnout was more negatively related to work outcomes (consequences) such as poor job satisfaction, physical and emotional symptoms, turnover intention, and perceived performance level than stress.

The distinction between stress and burnout is important to gauge the extent to which supervisor-subordinate fit impacts subordinates' occupational well-being. If fit only predicts subordinates' stress (but not burnout), this would minimally provide support for the idea that supervisor-subordinate fit influences episodic negative emotional experiences. However, if fit also predicts burnout, this would provide greater support for the contention that supervisor-subordinate fit influences sustained experiences of psychological distress. Given that supervisor and subordinates interact frequently on a regular basis, we hypothesized that supervisor-subordinate fit would influence both burnout and stress in the following ways:

Hypothesis 1: Low NFCC subordinates will experience more burnout and stress if their supervisors use harsh power tactics.

Hypothesis 2: High NFCC subordinates will experience less burnout and stress when facing harsh power tactics.

Hypothesis 3: Low NFCC subordinates will experience less burnout and stress if their supervisors use soft power tactics.

Hypothesis 4: High NFCC subordinates will experience more burnout and stress when their supervisors use soft power tactics.

\section{Study 1}

The aim of Study 1 was to examine our specific hypotheses with regard to the interactive effect of subordinates' NFCC and supervisors' power tactics on subordinates' burnout. To this effect, Study 1 took place in a hospital.

\section{Method}

\section{Participants}

Ninety Italian hospital nurses (23 men and 67 women, $\left.M_{\text {age }}=46.14, S D_{\text {age }}=8.00\right)$ participated in the study on a voluntary basis. The hospital, where the questionnaires were administered, employed approximately 120 nurses.

\section{Procedure}

Participants filled out the NFCC scale followed by a measure of power tactics used by their supervisors, and a measure of burnout. The questionnaires administered to subordinates included an introductory letter in which the purpose of the study was explained. They were told that the study would examine the relations between supervisors and workers in conflict situations. The anonymity of the participants was guaranteed.

$N F C C$. Participants responded to the Italian version of the Revised Need for Closure Scale (Rev NfCS, Pierro \& Kruglanski, 2005). This scale is a brief 14-item self-report instrument designed to assess stable individual differences in the NFCC (e.g., "Any solution to a problem is better than remaining in a state of uncertainty"). Participants responded to these items on a 6-point Likert scale ranging from 1 (strongly disagree) to 6 (strongly agree). A composite NFCC score was computed by averaging the responses. The reliability of the scale was satisfactory $(M=3.76, S D=.71, \alpha=.70)$.

Supervisor's use of power tactics as perceived by the subordinates. To examine supervisors' use of power tactics as perceived by subordinates, we asked participants to respond to the Italian version (Pierro et al., 2012) of the Interpersonal Power Inventory (IPI, Raven et al., 1998). This IPI format uses a critical-incident technique where participants are told:

Often supervisors ask subordinates to do their job somewhat differently. Sometimes subordinates resist doing so or do not follow the supervisor's directions exactly. Other times, they will do exactly as their supervisor requests. We are interested in examining what behaviours supervisors use to gain compliance.

Then, participants were presented with 33 statements (e.g., "My supervisor reminds me that he/she could help me receive special benefits if I comply") representing the 11 tactics delineated by the IPIM (three items for each tactic). Respondents were then asked to indicate, for each statement, how often his or her supervisor uses these particular power tactics in order to gain compliance. Responses were made on a 7-point Likert scale ranging from 1 (very rarely) to 7 (very often). Prior research on social power has clustered the 11 power tactics into harsh and soft power tactics (Pierro et al., 2008, 2012; Raven et al., 1998; Schwarzwald et al., 2004). Based on this research, we conducted a factor analysis with Oblimin rotation. Consistent with prior research, a two-factor solution was obtained. The first factor accounted for $19.38 \%$ of the variance and included the following soft power tactics and loadings: Information (.98), Expertise (.35) Reference (.51), and Dependence (.63). The second factor explained $36.36 \%$ of variance and was composed of the following harsh power tactics: Reciprocity (.75), Position (.73), Equity (.68), Personal Reward (.67), Impersonal Reward (.75), Personal Coercion (.78), and Impersonal coercion (.76). Harsh $(M=2.91, S D=1.15, \alpha=.87)$ and soft $(M=3.48, S D=1.07, \alpha=.73)$ power tactics were both found to be reliable. 
Burnout. Participants responded to the Italian version (Pierro \& Fabbri, 1994) of the Maslach Burnout Inventory (MBI; Maslach et al., 1996). The MBI is a 22item self-report instrument designed to assess burnout in helping professions. Specifically, the MBI measures the three following constructs: EE, depersonalization (DP), and personal accomplishment (PA). The EE subscale (nine items) assesses feelings of emotional vulnerability and exhaustion in one's work. The DP subscale (five items) assesses impersonal response towards the objects of one's work. The PA subscale (eight items) assesses feelings of competence and successful achievement related to one's work. High scores on the EE or DP scales or low scores on the PA scale indicate high levels of burnout. The $\mathrm{EE}(M=2.72, S D=.95, \alpha=.84), \mathrm{DP}(M=2.24, S D=.97$, $\alpha=.71)$, and PA $(M=4.22, S D=.82, \alpha=.74)$ scales were shown to be reliable. Because the three subscales were significantly correlated with each other (EE and DP, $r$ $(88)=.64 ; p<.001 ; \mathrm{EE}$ and $\mathrm{PA}, r(88)=-.48$; $p<.001 ;$ DP and PA, $r(88)=-.58 ; p<.001)$ we created an index of burnout $(\alpha=.89)$ by averaging these three measures once PA had been reverse scored (see Kim \& Ji, 2009 , for research supporting the presence of a common underlying construct of burnout).

\section{Results}

A summary of descriptive statistics and zero-order correlations between the variables is shown in Table 1. The fit predictions between subordinates' NFCC and supervisors' use of harsh and soft power tactics on burnout were tested via hierarchical moderated multiple regression analyses ${ }^{3}$. To reduce the potential threat of multi-collinearity, continuous predictor variables were mean-centred and interaction terms were created based on these centred values (Aiken \& West, 1991). The variance inflation factor (VIF) for each variable was below 10 (the highest VIF value was 1.90); therefore we found no support for the existence of multi-collinearity (Hair, Black, Babin,
Table 2. Results of hierarchical moderated regression for burnout (Study 1).

\begin{tabular}{lccc}
\hline & Step 1 & Step 2 & Step 3 \\
\hline Age & .00 & .00 & .00 \\
Gender & .02 & .00 & -.03 \\
Harsh tactics & $.25^{* *}$ & $.25^{* *}$ & .15 \\
Soft tactics & -.10 & -.10 & -.02 \\
Need for closure & & .04 & .06 \\
Harsh $\times$ need for closure & & & $-.48^{* * *}$ \\
Soft $\times$ need for closure & & & $.35^{* * *}$ \\
$R^{2}$ & .07 & .07 & $.24^{* * *}$ \\
Adjusted $R^{2}$ & .03 & .01 & .18 \\
$\Delta R^{2}$ & .07 & .00 & $.17^{* * *}$ \\
\hline
\end{tabular}

Notes: $* * p<.01$ and $* * * p<.001$.

Anderson, \& Tatham, 2006). Results of the analyses are summarized in Table 2.

Specifically, results in model 1 indicated that the effect of harsh power tactics $(\mathrm{B}=.25, S E=.10, p=.01)$ on burnout was significant, but not for soft power tactics $(\mathrm{B}=-.10$, $S E=.10, p=.31)$, age $(\mathrm{B}=.00, S E=.01, p=.62)$, or gender $(\mathrm{B}=.02, S E=.18, p=.90)$. The model did not significantly improve by adding need for closure $\left(\Delta R^{2}=.00, \Delta F=.23\right.$, $p=.62)$ as it was unrelated to burnout $(\mathrm{B}=.04, S E=.08$, $p=.48)$. Hypotheses $1-4$ were tested in model 3 by adding the interaction terms between need for closure and harsh/soft power tactics $\left(\Delta R^{2}=.17, \Delta F=9.32, p=.001\right)$. As predicted, the interaction between NFCC and harsh power tactics was significant $(\mathrm{B}=-.48, S E=.11, p<.001)$. To further analyse this interaction effect, we carried out simple slopes analyses (Aiken \& West, 1991). These analyses indicated that harsh power tactics were negatively associated with burnout for individuals with high levels of NFCC (1 SD above the mean), $\mathrm{B}=-.32, S E=.16, p<.05$. In contrast, harsh power tactics were positively associated with burnout for individuals with low levels of NFCC (1 SD below the mean), $\mathrm{B}=.61, S E=.12, p<.001$. These results support hypotheses 1 and 2 . These results are displayed in Figure 1a.

Table 1. Means, standard deviations, and correlations involving all variables (Study 1).

\begin{tabular}{|c|c|c|c|c|c|c|c|c|c|c|}
\hline & $M$ & $S D$ & 1 & 2 & 3 & 4 & 5 & 6 & 7 & 8 \\
\hline 1) Need for closure & 3.76 & .71 & $(.70)$ & & & & & & & \\
\hline 2) Harsh tactics & 2.91 & 1.15 & -.06 & $(.87)$ & & & & & & \\
\hline 3) Soft tactics & 3.48 & 1.07 & -.07 & $.62 * * *$ & $(.73)$ & & & & & \\
\hline 4) $\mathrm{EE}$ & 2.72 & .95 & $.23 *$ & $.22 *$ & .11 & $(.84)$ & & & & \\
\hline 5) $\mathrm{DP}$ & 2.24 & .97 & -.06 & $.34 * * *$ & .16 & $.64 * * *$ & $(.71)$ & & & \\
\hline 6) $\mathrm{PA}$ & 4.22 & .82 & -.12 & -.08 & .07 & $-.48 * * *$ & $-.58 * * *$ & $(.74)$ & & \\
\hline 7) Burnout (overall) & 2.63 & .77 & .05 & $.24 *$ & .07 & $.88 * * *$ & $.84 * * *$ & -.80 & $(.89)$ & \\
\hline 8) Age & 46.14 & 8.00 & .17 & -.02 & .20 & .04 & .07 & -.05 & .01 & \\
\hline 9) Gender & .74 & .43 & $.21 *$ & -.03 & .03 & .07 & .03 & -.12 & -.00 & .02 \\
\hline
\end{tabular}

Notes: $\mathrm{EE}=$ emotional exhaustion; $\mathrm{DP}=$ depersonalization; $\mathrm{PA}=$ personal accomplishment.

${ }^{*} p<.05$ and ${ }^{* * *} p<.001$. Cronbach's alphas are displayed in brackets. 

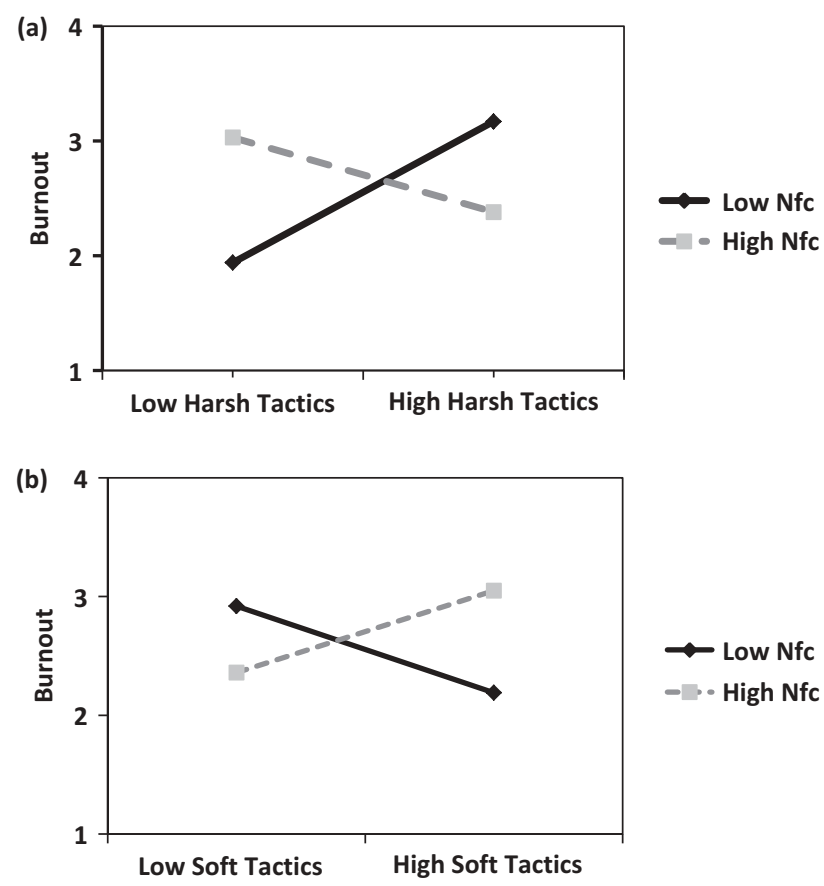

Figure 1. (a) Subordinates' burnout as a function of supervisors' harsh power tactics and subordinates need for closure (Study 1). (b) Subordinates' burnout as a function of supervisors' soft power tactics and subordinates need for closure (Study 1).

Furthermore, the interaction between NFCC and soft tactics was significant $(\mathrm{B}=.35, S E=.10, p=.002)$. Results of simple slopes analyses (Aiken \& West, 1991) indicated that soft power tactics were positively associated with burnout for individuals with high levels of NFCC ( $1 S D$ above the mean), B $=.34, S E=.14, p<.05$. In contrast, soft power tactics were negatively associated with burnout for individuals with low levels of NFCC ( $1 S D$ below the mean), $\mathrm{B}=-.36, S E=.14, p<.05$. These results support hypotheses 3 and 4 . These results are displayed in Figure 1b.

\section{Discussion}

The results of Study 1 provided support for the notion of fit between supervisors' power tactics and subordinates' NFCC in experiencing burnout. Specifically, the present results indicated that individuals with high levels of NFCC experienced more burnout when they perceived their supervisors as using soft power tactics and experienced less burnout when they perceived their supervisors as using harsh power tactics. These results are contrasted with individuals with low levels of NFCC for whom soft (vs. harsh) power tactics are associated with less (vs. more) burnout. Overall, these results suggest that power tactics have differential impact on burnout depending on subordinates' motivational concern and tolerance for ambiguity (NFCC).

\section{Study 2}

The aim of Study 2 was first to replicate Study 1 by examining the fit hypothesis in different organizational settings while using a different measure of psychological well-being at work (i.e., stress) to extend the generalizability of our findings. Furthermore, Study 2 aimed to address the problem of common-method bias (i.e., subordinates reporting their NFCC and their supervisors' power tactics) found in Study 1, which might have inflated the magnitude of the reported relationships (Podsakoff, MacKenzie, Lee, \& Podsakoff, 2003). To this end, Study 2 asked supervisors to report their own use of soft and harsh power tactics on their subordinates.

\section{Method \\ Participants}

One hundred and twelve employees (64 men and 48 women, $M_{\text {age }}=34.78, S D_{\text {age }}=7.01$ ) from two Italian service organizations (a non-profit organization for professional education, $N=80$, and a maintenance service organization, $N=32$ ), divided in 30 units (work groups; 24 from the first organization and six from the second organization) participated in the study on a voluntary basis. Mean group size was $3.73(S D=1.11)$.

\section{Procedure}

In the present study, both subordinates and supervisors were assessed independently. Subordinates filled out the NFCC scale and a measure of perceived stress at work. Supervisors, on the other hand, provided ratings of their own use of power tactics on their subordinates. Thirty supervisors were surveyed.

NFCC. Akin to Study 1, participants responded to the Italian version of the Revised NFCC scale (Pierro \& Kruglanski, 2005).

Reliability of the scale was satisfactory $(M=3.43$, $S D=.75, \alpha=.85)$.

Supervisor use of power tactics. To examine supervisors' use of power tactics we used the IPI usage scale, Supervisor's Format (Pierro et al., 2012). This format is an adapted version of the IPI wherein supervisors are told:

Often supervisors ask subordinates to do their job somewhat differently. Sometimes subordinates resist doing so or do not follow the supervisor's directions exactly. Other times, they will do exactly as their supervisor requests. We are interested in examining what behaviours supervisors use to gain compliance.

Subsequently, supervisors were presented with 33 statements assessing how they generally attempt to influence their subordinates (e.g., "I remind the worker that I 
Table 3. Means, standard deviations, and correlations involving all Variables (Study 2).

\begin{tabular}{lcccccccc}
\hline & $M$ & $S D$ & 1 & 2 & 3 & 4 & 5 & 6 \\
\hline 1) Need for closure & 3.43 & 0.75 & $(.85)$ & & & & & \\
2) Harsh tactics & 2.41 & 0.66 & .17 & $(.89)$ & & & & \\
3) Soft tactics & 4.26 & 0.78 & $.46^{* * *}$ & $.75^{* * *}$ & $(.77)$ & & & \\
4) Stress & 3.07 & 1.12 & $.29 * * *$ & -.00 & .01 & $(.88)$ & & \\
5) Type of organization & 0.29 & 0.45 & -.02 & .05 & -.16 & -.14 & & \\
6) Age & 34.78 & 7.01 & $.19 *$ & .06 & .05 & -.04 & $.58^{* * *}$ & \\
7) Gender & 0.43 & .49 & -.02 & -.17 & -.10 & .15 & $-.22^{*}$ & $-.25^{*}$ \\
8) Seniority & 5.73 & 5.53 & $.32 * * *$ & $.21^{*}$ & $.26^{*}$ & .02 & .12 & $.45^{* * *}$ \\
\hline
\end{tabular}

Notes: ${ }^{*} p<.05,{ }^{* * *} p<.001$; Cronbach's alphas are displayed in brackets.

can help him/her receive special benefits if he/she complies"). These statements represent the 11 power tactics delineated by the IPIM (three items per tactic). Eleven representative items, one for each power tactic, are presented in Appendix A. Responses were made on a 7-point Likert scale ranging from 1 (very rarely) to 7 (very often). As in Study 1, we clustered the 11 power tactics into harsh and soft power tactics. Reliability of these two dimensions was satisfactory for both harsh $(M=2.41$, $S D=.66, \alpha=.89)$ and soft $(M=4.26, S D=.78$, $\alpha=.77)$ power tactics.

Stress. Stress was measured with five items derived from the Perceived Stress Scale (Cohen, Kamarck, \& Mermelstein, 1983). Sample items: "In the last month, I often felt nervous and stressed" and "In the last month, I often felt unable to control the important things in my life". Participants responded on a 6-point Likert scale ranging from 1 (strongly disagree) to 6 (strongly agree). A composite score of perceived stress was computed by averaging responses. Reliability of the Perceived Stress Measure was satisfactory $(M=3.07, S D=1.12, \alpha=.88)$.

\section{Results}

Our hypotheses were tested using hierarchical linear modelling (HLM) with HLM 6.0 (Raudenbush, Bryk, \& Congdon, 2004). HLM is appropriate in the case of nested data structure with predictors at different levels and a dependent variable at the lowest level of analysis (Snijders \& Bosker, 1999). In our dataset, subordinates were nested within teams (each team having a unique supervisor). We entered (a) subordinates' NFCC at the individual level, (b) supervisors' harsh and soft power tactics at the group level, and (c) the cross-level interactions between these variables (i.e., "NFCC $\times$ harsh power" and "NFCC $\times$ soft power"). The type of organization was entered as a control variable at the group level of analysis. Akin to Study 1, to reduce the potential threat of multi-collinearity, continuous predictor variables were standardized and interaction terms were created based on these values (Aiken \& West, 1991). No sign of multi-collinearity was found between variables (highest VIF value was 2.63). Table 3 contains a summary of descriptive statistics and zero-order correlations between the variables. The following HLM analyses were conducted with the restricted maximum likelihood method of estimation. Unstandardized coefficients are reported in Table 4.

Results indicated no main effect of age $(\mathrm{B}=.00$, $S E=.02, p=.65)$, gender $(\mathrm{B}=.34, S E=.21, p=.11)$, seniority $(\mathrm{B}=.00, S E=.02, p=.89)$, need for closure $(\mathrm{B}=.21, S E=.16, p=.19)$, type of organization $(\mathrm{B}=-.36, S E=.40, p=.36)$, harsh $(\mathrm{B}=.07, S E=.34$, $p=.82)$, or soft power $(\mathrm{B}=-.08, S E=.30, p=.79)$ tactics on stress. As expected, subordinates' NFCC interacted with their supervisors' use of harsh $(\mathrm{B}=-.97, S E=.35$, $p=.01)$ and soft $(\mathrm{B}=.94, S E=.37, p=.01)$ power tactics in determining stress. Follow-up simple slope tests (Aiken $\&$ West, 1991) for the NFCC $\times$ harsh power tactics interaction indicated that for individuals high on NFCC (i.e., $1 S D$ unit above the mean), the harsher the power tactics, the lesser the subordinates experienced stress $(\mathrm{B}=-.89, S E=.34, t=-2.58, p=.01)$. On the other hand, for individuals low on NFCC (i.e., $1 S D$ unit below

Table 4. Results of multilevel analyses on stress (Study 2).

\begin{tabular}{lc}
\hline Criteria & Stress \\
\hline & $\mathrm{B}$ \\
Level-1 variable & .00 \\
Age & .34 \\
Gender & .00 \\
Seniority & .21 \\
Need for closure (NFC) & \\
Level-2 variables & -.36 \\
Type of organization ${ }^{\mathrm{a}}$ & .07 \\
Harsh tactics & -.08 \\
Soft tactics & $-.97 * * *$ \\
NFC $\times$ harsh & $.94^{* * *}$ \\
NFC $\times$ soft &
\end{tabular}

Notes: ${ }^{\mathrm{a}} 0=$ professional education service organization, $1=$ maintenance service organization.

$* * * p<.001$. 
the mean), the harsher the power tactics, the more the subordinates experienced stress $(\mathrm{B}=1.05, S E=.40$, $t=2.60, p=.01$ ). Figure 2 a displays the results.

Follow-up simple slope tests (Aiken \& West, 1991) were also conducted for the NFCC $\times$ soft power tactics interaction. Results indicated that for individuals high on NFCC (i.e., $1 S D$ unit above the mean), the softer the power tactics, the more the subordinates experienced stress $(\mathrm{B}=.86, S E=.33, t=2.573, p=.01)$. For individuals low on NFCC (i.e., $1 S D$ unit below the mean), the softer the power tactics, the lesser the subordinates experienced stress $(\mathrm{B}=-1.02, S E=.37, t=2.76$, $p=.01)$. Figure $2 \mathrm{~b}$ displays the results.

\section{Discussion}

Study 2 provided support for the proposed fit hypotheses between supervisors' power tactics and subordinates' NFCC on subordinates' stress. As such, Study 2 conceptually replicated across organizations the results of Study 1 using a different criterion of well-being, which extends the generalizability of our model. Furthermore, Study 2 measured supervisors' power tactics directly, thus addressing the common-method bias potentially found in Study 1 .

Contrary to Erkutlu et al. (2011), we found no relationship between power tactics (harsh or soft) and stress. Rather, our results demonstrated that the influence of power tactics on stress is conditional upon subordinates'

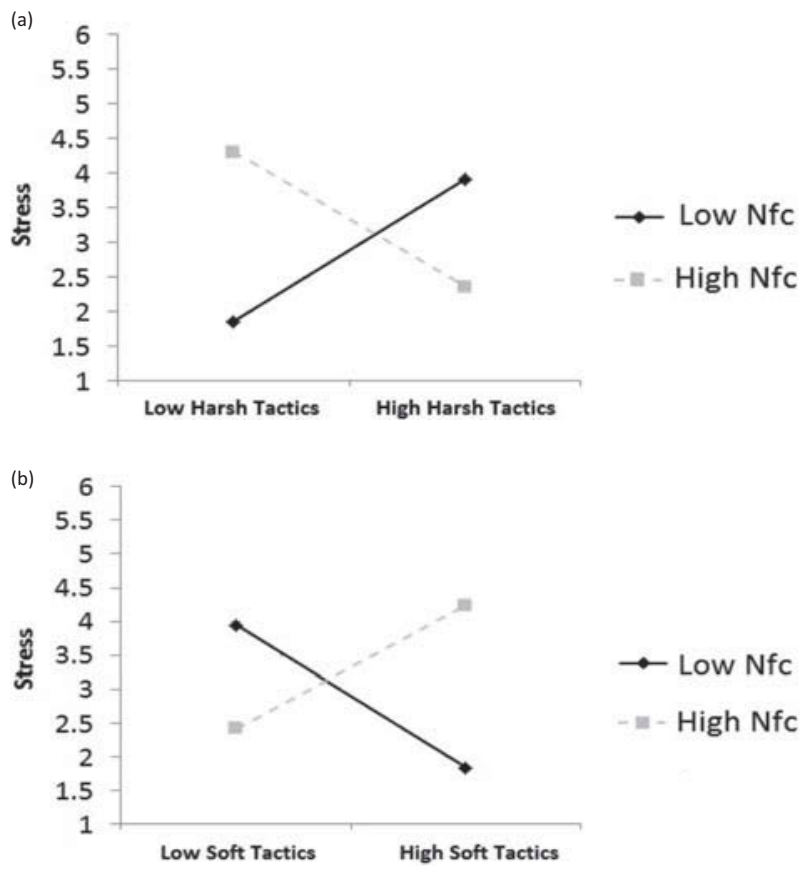

Figure 2. (a) Subordinates' stress as a function of supervisors' harsh power tactics and subordinates' need for closure (Study 2). (b) Subordinates' stress as a function of supervisors' soft power tactics and subordinates' need for closure (Study 2).
NFCC. Specifically, subordinates with high levels of NFCC reported less stress when they perceived their supervisors as using harsh power tactics, whereas these same individuals reported more stress when they perceived their supervisors as using soft power tactics on them. In contrast, individuals with low levels of NFCC were less prone to experience stress when they perceived their supervisors as using soft power tactics and relatively more stress when they perceived their supervisors as using harsh power tactics. These results thus suggest that soft power tactics are not always associated with better outcomes, nor are harsh power tactics necessarily deleterious to subordinates.

\section{General discussion}

Two studies conducted in different organizational settings provided support for the influence of fit between subordinates' NFCC (person) and supervisors' power tactics (environment) on subordinates' burnout and stress. Specifically, subordinates with high levels of NFCC reported less burnout and stress when exposed to harsh power tactics from their supervisors, whereas subordinates with low levels of NFCC reported more burnout and stress. The opposite pattern of results was shown for soft power tactics: subordinates with low levels of NFCC reported less burnout and stress, whereas high NFCC subordinates exposed to those tactics reported greater burnout and stress. Overall, these results replicate the power tactics-need for closure interaction found by Pierro et al. (2012) on a new outcome variable, namely subordinates' occupational well-being.

\section{Contributions}

In addition to demonstrating the importance of the $\mathrm{P}-\mathrm{E}$ fit in organizational setting (Judge \& Ferris, 1992; Kristof, 1996; Schneider et al., 1995), the present research makes several contributions relevant to the IPIM (Raven et al., 1998). One such contribution comes from documenting several psychological well-being criteria. Whereas prior research has uniquely focused on stress, we demonstrated consistent patterns of results with all three components of burnout (i.e., EE, DP, and PA). The present research thus supports the contention that the influence of supervisorsubordinate fit on psychological well-being is not limited to a single criterion of mental health. The implications of these results are twofold. First, using distinct measures of well-being reinforces the validity of our findings. Second, it demonstrates that supervisor-subordinate fit is also related to sustained experiences of psychological distress (i.e., burnout), an important aspect the stress scale did not necessarily capture in prior research.

More importantly, by evincing the interaction between supervisors' power tactics and subordinates' 
NFCC, our findings nuance the idea that soft power tactics systematically yield better organizational outcomes (Pierro et al., 2013; Raven et al., 1998; Schwarzwald et al., 2001). Specifically, whereas prior research by Erkutlu et al. (2011) indicated that soft power tactics are negatively associated with stress, the present work demonstrates that it is not always the case: subordinates that eschew ambiguity (high NFCC) experience more burnout and stress when their supervisors utilize soft power tactics. In contrast, low NFCC subordinates and soft power tactics are associated with less burnout and stress. The opposite findings were found for harsh power tactics. Taken together, the present results underscore that the dynamics of social power cannot be guided by a "one size fits all" approach. This observation prevents a simplistic view of subordinates' psychological well-being and supervisors' management strategies-an important distinction for organizations striving to promote employees' well-being.

\section{Practical implications}

The present work points to several important organizational implications for personnel selection and management. In terms of personnel selection, the results herein described suggest that subordinates and supervisors could be matched based on their respective predispositions (i.e., need for closure and power tactics, respectively) in order to promote better psychological well-being at work. This low-cost procedure would entail managers and human resources to survey the two constituents and proceed with forming work groups. This strategy could have great value given the pervasive influence of burnout and stress on a vast array of organizational phenomena such as turnover rates (Gupta \& Beehr, 1979), absenteeism (Karasek, 1979), and counterproductive work behaviour (Fox, Spector, \& Miles, 2001), which includes actions taken by employees to hurt the organization (e.g., sabotage, theft).

A second implication relates to personnel management. Notwithstanding that NFCC has been herein described as a stable individual difference, psychological research has demonstrated that it can also be affected by situational variations (e.g., noise, fatigue, and alcoholic intoxication, for a review see Kruglanski, 2004). In other words, individuals' NFCC tend to be stable over time (e.g., low NFCC); however, strong social forces can temporarily sway one's predisposition to the opposite side of the spectrum (i.e., high NFCC) - a phenomenon that has been documented for a large number of psychological constructs (e.g., locomotion/assessment; harmonious/obsessive passion; Bélanger, Lafrenière, Vallerand, \& Kruglanski, 2013b; Higgins, 2008; for a review see Kruglanski \& Sheveland, 2012). The present research prescribes that supervisors (1) recognize "strong situations" (i.e., with the help of appropriate training) that can temporarily increase or decrease their subordinates' need for closure and then (2) adjust their power tactics in order to create a situation of fit with their subordinates. For instance, if subordinates are working under high time constraint (a situation conducive to high NFCC; Kruglanski, 2004) then supervisors could prioritize harsh power tactics. Conversely, creative work which is facilitated by open-mindedness (low NFCC) and hindered by the experience of stress (Talbot, Cooper, \& Barrow, 1992) could be accomplished with softer power tactics. Overall, this managerial flexibility would allow supervisors to get the most out of their subordinates, while ensuring their psychological wellbeing within the organization.

A word of caution is to be said with regard to implementing the foregoing organizational strategies. Practitioners should not confound harsh power tactics with treating employees badly, nor should they mistaken soft tactics with being nonchalant or providing excessive care and kindness. Rather, harsh and soft power tactics should be understood as strategies that afford subordinates with different amounts of clarity and certainty.

\section{Future research}

One question that begs future research is whether the effect of fit on stress has a trickle-down effect on other organizational phenomena. It appears plausible that supervisor-subordinate fit contributes significantly to harmonious work relations by fostering trust, perceived justice, and better conflict management strategies between colleagues. These relationships could eventually become normative and inspire relationships across the organization. As such then, greater supervisorsubordinate fit could be an important pathway to harmonious organizational culture and climate (Ostroff, Kinicki, \& Tamkins, 2003). Clearly, future research is needed to test these hypotheses.

In a similar vein, previous research has shown that the fit between supervisors' power tactics and subordinates' NFCC is associated with greater subordinate performance (Pierro et al., 2012). A hypothesis worth testing is whether performance due to fit is mediated by EE and increased positive affect (see the broaden-and-build theory of positive emotions detailed by Fredrickson, 2001). The same idea could be applied to group performance. For instance, a work group composed predominantly of individuals with the same motivational concern for cognitive closure (high or low) may thrive more effectively as a function of its supervisors' power tactics.

As mentioned previously, subordinates' NFCC can be temporarily altered by strong situations. Although research has found some of them in laboratory settings 
(e.g., noise, time constraint), it would be interesting to investigate this topic in organizations. For instance, diary studies could help uncover additional circumstances that attenuate or accentuate subordinates' need for closure. Possibly, certain commonalities could be found across work settings, other situations could be job specific. Ultimately, these findings could guide supervisors in choosing the most appropriate power tactics for their organizations.

\section{Limitations}

A word of caution is called for as the present work relies primarily on correlational data, which limits the use of causal inferences to describe the relationship between need for closure and power tactics on subordinates' burnout and stress. It is theoretically possible that stress augments subordinates' NFCC. Future research should clarify these causal links by manipulating subordinates' need for closure in a laboratory setting.

In the same vein, reliance on cross-sectional research designs opens the door to counter-explanations, which reduces the validity of the present findings. For example, given supervisor-subordinate frequent social interactions, one could argue that supervisors' power tactics have the ability of shaping subordinates' NFCC, which in turn could influence subordinates' psychological well-being at work. The present research is not impervious to this counter-explanation and future research could test for this possibility using longitudinal designs.

\section{Conclusion}

The present research investigated the notion of fit (Judge \& Ferris, 1992; Schneider et al., 1995) between supervisors' power tactics and subordinates' NFCC on subordinates' burnout and stress. Harsh power tactics are associated with less burnout and stress for subordinates with a tendency to eschew ambiguity (high NFCC) and more burnout and stress for those who avoid binding conclusions (low NFCC). The opposite findings were found for soft power tactics. These results nuance prior findings suggesting that soft power tactics systematically yield more positive outcomes in organizational setting than harsh power tactics. Consequently, this research attests to the importance of understanding the notion of fit between supervisor and their subordinates.

\section{Disclosure statement}

No potential conflict of interest was reported by the authors.

\section{Notes}

1. Experimental evidence and case studies in management suggest that the reciprocity norm is a potent method for acquiring and maintaining power (e.g., Goranson \& Berkowitz, 1966; Gouldner, 1960; Kotter, 1979; Regan, 1971). Reciprocation wariness has been found to influence the exchange of resources in interpersonal relationships (Cotterell, Eisenberger, \& Speicher, 1992; Eisenberger, Cotterell, \& Marvel, 1987) and is thus conceived of as a harsh power tactic.

2. The need for closure is a distinct construct from the desire for control. The former refers to an epistemic motivation involved in the formation of judgments (subjective knowledge), whereas the latter pertains to the striving for social dominance.

3. Multiple regression analyses were also conducted on each Burnout inventory's subscales. These analyses yielded similar results to the overall index of burnout. Consequently, we comment solely on the latter.

\section{References}

Aiken, L. S., \& West, S. G. (1991). Multiple regression: Testing and interpreting interactions. Newbury Park, CA: Sage.

Bélanger, J. J., Lafrenière, M. A. K., Vallerand, R. J., \& Kruglanski, A. W. (2013a). Driven by fear: The effect of success and failure information on passionate individuals' performance. Journal of Personality and Social Psychology, 104, 180-195. doi:10.1037/a0029585

Bélanger, J. J., Lafrenière, M. A. K., Vallerand, R. J., \& Kruglanski, A. W. (2013b). When passion makes the heart grow colder: The role of passion in alternative goal suppression. Journal of Personality and Social Psychology, 104, 126-147. doi:10.1037/a0029679

Berkowitz, L., \& Daniels, L. R. (1963). Responsibility and dependency. The Journal of Abnormal and Social Psychology, 66, 429-436. doi:10.1037/h0049250

Cartwright, D. (1965). Influence, leadership, and control. In J. G. March (Ed.), Handbook of organizations (pp. 1-47). Chicago, IL: Rand-McNally.

Caton, D. J., Grossnickle, W. F., Cope, J. G., Long, T. E., \& Mitchell, C. C. (1988). Burnout and stress among employees at a state institution for mentally retarded persons. American Journal on Mental Retardation, 93, 300-304.

Cialdini, R. B. (1993). Influence. The psychology of persuasion (rev. ed.). New York, NY: Morrow.

Cohen, S., Kamarck, T., \& Mermelstein, R. (1983). A global measure of perceived stress. Journal of Health and Social Behavior, 24, 385-396.

Cooper, C. L., \& Payne, R. (Eds.). (1991). Personality and stress: Individual differences in the stress process. Chichester: Wiley.

Cotterell, N., Eisenberger, R., \& Speicher, H. (1992). Inhibiting effects of reciprocation wariness on interpersonal relationships. Journal of Personality and Social Psychology, 62, 658

De Grada, E., Kruglanski, A., Mannetti, L., \& Pierro, A. (1999). Motivated cognition and group interaction: Need for closure affects the contents and processes of collective negotiations. Journal of Experimental Social Psychology, 35, 346-365. doi:10.1006/jesp.1999.1376

Eisenberger, R., Cotterell, N., \& Marvel, J. (1987). Reciprocation ideology. Journal of Personality and Social Psychology, 53, 743-750. doi:10.1037/0022-3514.53.4.743 
Elliot, A. J., \& Sheldon, K. M. (1997). Avoidance achievement motivation: A personal goals analysis. Journal of Personality and Social Psychology, 73, 171-185. doi:10.1037/00223514.73.1.171

Erchul, W. P., Raven, B. H., \& Whichard, S. M. (2001). School psychologist and teacher perceptions of social power in consultation. Journal of School Psychology, 39, 483-497. doi:10.1016/S0022-4405(01)00085-1

Erkutlu, H., Chafra, J., \& Bumin, B. (2011). Organizational culture's role in the relationship between power bases and job stress. Hacettepe University Journal of Education, 40, 198-209.

Etzioni, A. (1961). A comparative analysis of complex organizations. Nova York: The Free Press of Glencoe.

Fox, S., Spector, P. E., \& Miles, D. (2001). Counterproductive work behavior $(\mathrm{CWB})$ in response to job stressors and organizational justice: Some mediator and moderator tests for autonomy and emotions. Journal of Vocational Behavior, 59, 291-309. doi:10.1006/jvbe.2001.1803

Fredrickson, B. L. (2001). The role of positive emotions in positive psychology: The broaden and-build theory of positive emotions. American Psychologist, 56, 218-226. doi:10.1037/0003-066X.56.3.218

French, J. R. P., \& Raven, B. H. (1959). The bases of social power. In D. Cartwright (Ed.), Studies in social power (pp. 150-167). Ann Arbor, MI: Institute for Social Research.

Goranson, R. E., \& Berkowitz, L. (1966). Reciprocity and responsibility reactions to prior help. Journal of Personality and Social Psychology, 3, 227-232. doi:10.1037/h0022895

Gouldner, A. (1960). The norm of reciprocity: A preliminary statement. American Sociological Review, 25, 161-178.

Gupta, B., \& Sharma, N. K. (2008). Compliance with bases of power and subordinates' perception of superiors: Moderating effect of quality of interaction. Singapore Management Review, 30, 1-24.

Gupta, N., \& Beehr, T. A. (1979). Job stress and employee behaviors. Organizational Behavior And Human Performance, 23, 373-387. doi:10.1016/0030-5073(79) 90004-7

Hair, J. F., Black, W. C., Babin, B. J., Anderson, R. E., \& Tatham, R. L. (2006). Multivariate data analysis (Vol. 6). Upper Saddle River, NJ: Pearson Prentice Hall.

Harvey, L. O., Jr, Hammond, K. R., Lusk, C. M., \& Mross, E. F. (1992). The application of signal detection theory to weather forecasting behavior. Monthly Weather Review, 120, 863883. doi:10.1175/1520-0493(1992)120<0863:TAOSDT $>2.0$. $\mathrm{CO} ; 2$

Hayes, C. T., \& Weathington, B. L. (2007). Optimism, stress, life satisfaction, and job burnout in restaurant managers. The Journal of Psychology, 141, 565-579. doi:10.3200/ JRLP.141.6.565-580

Higgins, E. T. (2008). Culture and personality: Variability across universal motives as the missing link. Social and Personality Psychology Compass, 2, 608-634. doi:10.1111/j.17519004.2007.00075.x

Hinkin, T. R., \& Schriesheim, C. A. (1990). Relationships between subordinate perceptions of supervisor influence tactics and attributed bases of supervisory power. Human Relations, 43, 221-237. doi:10.1177/001872679004300302

Hobfoll, S. E., \& Shirom, A. (2000). Conservation of resources theory: Applications to stress and management in the workplace. In R. T. Golembiewski (Ed.), Handbook of organization behaviour (2nd ed., pp. 57-81). New York, NY: Dekker.
Hogg, M. A. (1992). The social psychology of group cohesiveness: From attraction to social identity. London: Harvester Wheatsheaf.

Hogg, M. A., \& Reid, S. A. (2001). Social identity, leadership, and power. In A. Y. Lee-Chai \& J. A. Bargh (Eds.), The use and abuse of power: Multiple perspectives on the causes of corruption (pp. 159-180). Philadelphia, PA: Psychology Press.

Jost, J. T., Glaser, J., Kruglanski, A. W., \& Sulloway, F. J. (2003). Political conservatism as motivated social cognition. Psychological Bulletin, 129, 339-375. doi:10.1037/00332909.129.3.339

Judge, T. A., \& Ferris, G. R. (1992). The elusive criterion of fit in human resource staffing decisions. Human Resource Planning, 15, 47-67.

Karasek, R. A., Jr. (1979). Job demands, decision latitude, and strain: Implications for job redesign. Administrative Science Quarterly, 24, 285-308.

Kim, H., \& Ji, J. (2009). Factor structure and longitudinal invariance of the Maslach Burnout Inventory. Research on Social Work Practice, 19, 325-339. doi:10.1177/ 1049731508318550

Koslowsky, M., \& Schwarzwald, J. (2001). The power interaction model. Theory, Methodology, and empirical applications. In A. Y. Lee-Chai \& J. A. Bargh (Eds.), The use and abuse of power: Multiple perspectives on the causes of corruption (pp. 195-214). Ann Arbor, MI: Psychology Press.

Koslowsky, M., Schwarzwald, J., \& Ashuri, S. (2001). On the relationship between subordinates' compliance to power sources and organisational attitudes. Applied Psychology, 50, 455-476. doi:10.1111/apps.2001.50.issue-3

Kotter, J. P. (1979). Power in management. New York, NY: AMACOM.

Kristof, A. L. (1996). Person-organization fit: An integrative review of its conceptualizations, measurement, and implications. Personnel Psychology, 49, 1-49. doi:10.1111/ peps.1996.49.issue-1

Kristof-Brown, A. L., Zimmerman, R. D., \& Johnson, E. C. (2005). Consequences of individuals' fit at work: A metaanalysis of person-job, person-organization, person-group, and person-supervisor fit. Personnel Psychology, 58, 281342. doi:10.1111/peps.2005.58.issue-2

Kruglanski, A. W. (2004). The psychology of closed mindedness. New York, NY: Psychology Press.

Kruglanski, A. W., Pierro, A., Higgins, E. T., \& Capozza, D. (2007). "On the move" or "staying put": Locomotion, need for closure, and reactions to organizational change. Journal of Applied Social Psychology, 37, 1305-1340. doi:10.1111/ jasp.2007.37.issue-6

Kruglanski, A. W., Pierro, A., Mannetti, L., \& De Grada, E. (2006). Groups as epistemic providers: Need for closure and the unfolding of group centrism. Psychological Review, 113, 84-100. doi:10.1037/0033-295X.113.1.84

Kruglanski, A. W., Shah, J. Y., Pierro, A., \& Mannetti, L. (2002). When similarity breeds content: Need for closure and the allure of homogeneous and self-resembling groups. Journal of Personality and Social Psychology, 83, 648-662. doi:10.1037/0022-3514.83.3.648

Kruglanski, A. W., \& Sheveland, A. (2012). Thinkers' personalities: On individual differences in the processes of sense making. In S. T. Fiske \& C. N. Macrae (Eds.), The SAGE handbook of social cognition (pp. 474-493). London: Sage Publications Limited. 
Kruglanski, A. W., \& Webster, D. M. (1991). Group members' reactions to opinion deviates and conformists at varying degrees of proximity to decision deadline and of environmental noise. Journal of Personality and Social Psychology, 61, 212-225. doi:10.1037/0022-3514.61.2.212

Kruglanski, A. W., \& Webster, D. M. (1996). Motivated closing of the mind: "Seizing" and "freezing". Psychological Review, 103, 263-283. doi:10.1037/0033-295X.103.2.263

Kruglanski, A. W., Webster, D. M., \& Klem, A. (1993). Motivated resistance and openness to persuasion in the presence or absence of prior information. Journal of Personality and Social Psychology, 65, 861-876. doi:10.1037/00223514.65.5.861

Landeweerd, J. A., \& Boumans, N. P. G. (1994). The effect of work dimensions and need for autonomy on nurses' work satisfaction and health. Journal of Occupational and Organizational Psychology, 67, 207-217. doi:10.1111/ j.2044-8325.1994.tb00563.x

Lazarus, R. S. (1966). Psychological stress and the coping process. New York, NY: McGraw-Hill.

Lazarus, R. S., \& Folkman, S. (1984). Stress appraisal and coping. New York, NY: Springer.

Livi, S., De Grada, E., Pierro, A., Mannetti, L., Kruglanski, A. W., \& Kenny, D. A. (2007). Bisogno di Chiusura Cognitiva e trasmissione di norme sperimentalmente indotte in piccoli gruppi. Giornale Italiano Di Psicologia, 3, 581-601.

Maslach, C., Jackson, S. E., \& Leiter, M. P. (1996). Maslach Burnout Inventory: Manual (3rd ed.). Palo Alto, CA: Consulting Psychologists Press.

Muchinsky, P. M., \& Monahan, C. J. (1987). What is personenvironment congruence? Supplementary versus complementary models of fit. Journal of Vocational Behavior, 31, 268-277. doi:10.1016/0001-8791(87)90043-1

Ostroff, C., Kinicki, A. J., \& Tamkins, M. M. (2003). Organizational culture and climate. In W. C. Borman, D. R. Ilgen, \& R. J. Klimoski (Eds.), Comprehensive handbook of psychology: Industrial and organizational psychology (Vol. 12, pp. 565-594). New York, NY: Wiley.

Peters, H. J., Greenberg, J., Williams, J. M., \& Schneider, N. R. (2005). Applying terror management theory to performance: Can reminding individuals of their mortality increase strength output. Journal of Sport \& Exercise Psychology, 27, 111-116.

Pierro, A., Cicero, L., Bonaiuto, M., Van Knippenberg, D., \& Kruglanski, A. W. (2005). Leader group prototypicality and leadership effectiveness: The moderating role of need for cognitive closure. The Leadership Quarterly, 16, 503-516. doi:10.1016/j.leaqua.2005.06.002

Pierro, A., Cicero, L., \& Raven, B. H. (2008). Motivated compliance with bases of social power. Journal of Applied Social Psychology, 38, 1921-1944. doi:10.1111/ j.1559-1816.2008.00374.X

Pierro, A., \& Fabbri, S. (1994). Burnout e Job Involvement: Un modelo di equazioni strutturali per variabili latenti. Bollettino Di Psicologia Applicata, 212, 67-73.

Pierro, A., \& Kruglanski, A. W. (2005). Revised need for cognitive closure scale (Unpublished manuscript). Università di Roma, "La Sapienza", Rome.

Pierro, A., Kruglanski, A. W., \& Raven, B. H. (2012). Motivational underpinnings of social influence in work settings: Bases of social power and the need for cognitive closure. European Journal of Social Psychology, 42, 4152. doi:10.1002/ejsp.v42.1

Pierro, A., Mannetti, L., De Grada, E., Livi, S., \& Kruglanski, A. W. (2003). Autocracy bias in informal groups under need for closure. Personality and Social Psychology Bulletin, 29, 405-417. doi:10.1177/0146167203251191

Pierro, A., \& Raven, B. H. (2006). Basi del potere sociale: 1'Interpersonal Power/Interaction Model. In A. Pierro (Ed.), Prospettive psicologiche sociali sul potere (pp. 141-162). Milano: Franco Angeli.

Pierro, A., Raven, B. H., Amato, C., \& Bélanger, J. J. (2013). Bases of social power, leadership styles, and organizational commitment. International Journal of Psychology, 48, 1122 1134. doi:10.1080/00207594.2012.733398

Pines, A. M., \& Keinan, G. (2005). Stress and burnout: The significant difference. Personality and Individual Differences, 39, 625-635. doi:10.1016/j.paid.2005.02.009

Podsakoff, P. M., MacKenzie, S. B., Lee, J.-Y., \& Podsakoff, N. P. (2003). Common method biases in behavioral research: A critical review of the literature and recommended remedies. Journal of Applied Psychology, 88, 879-903. doi:10.1037/0021-9010.88.5.879

Raudenbush, S. W., Bryk, A. S., \& Congdon, R. (2004). HLM 6.0. Lincolnwood, IL: Scientific Software International.

Raven, B. H. (1965). Social influence and power. In I. D. Steiner \& M. Fishbein (Eds.), Current studies in social psychology (pp. 371-382). New York, NY: Holt, Reinhart \& Winston.

Raven, B. H. (1992). A power/interaction model of interpersonal influence: French and Raven thirty years later. Journal of Social Behavior and Personality, 7, 217-244.

Raven, B. H. (1993). The bases of power: Origins and recent developments. Journal of Social Issues, 49, 227-251. doi:10.1111/josi.1993.49.issue-4

Raven, B. H. (2001). Power/interaction and interpersonal influence: Experimental investigations and case studies. In A. Lee-Chai \& J. Bargh (Eds.), The use and abuse of power: Multiple perspectives on the causes of corruption (pp. 217-240). New York, NY: Psychology Press.

Raven, B. H. (2004). Six bases of power. In G. R. Goethals, J. MacGregor Burns, \& G. J. Sorenson (Eds.), Encyclopedia of leadership. Thousand Oaks, CA: Sage Publications.

Raven, B. H. (2008). The bases of power and the power/interaction model of interpersonal influence. Analyses of Social Issues and Public Policy, 8, 1-22. doi:10.1111/j.15302415.2008.00159.x

Raven, B. H., \& Kruglanski, A. W. (1970). Conflict and power. In P. G. Swingle (Ed.), The structure of conflict (pp. 69109). New York, NY: Academy Press.

Raven, B. H., Schwarzwald, J., \& Koslowsky, M. (1998). Conceptualizing and measuring a power/interaction model of interpersonal influence. Journal of Applied Social Psychology, 28, 307-332. doi:10.1111/jasp.1998.28.issue-4

Regan, D. T. (1971). Effects of a favor and liking on compliance. Journal of Experimental Social Psychology, 7, 627-639. doi:10.1016/0022-1031(71)90025-4

Schneider, B., Goldstiein, H. W., \& Smith, D. B. (1995). The ASA framework: An update. Personnel Psychology, 48, 747-773. doi:10.1111/peps.1995.48.issue-4

Schwarzwald, J., Koslowsky, M., \& Agassi, V. (2001). Captains' leadership type and police officers' compliance to power bases. European Journal of Work and Organizational Psychology, 10, 273-290. doi:10.1080/13594320143000672

Schwarzwald, J., Koslowsky, M., \& Brody-Shamir, S. (2006). Factors related to perceived power usage in schools. British Journal of Educational Psychology, 76, 445-462.

Schwarzwald, J., Koslowsky, M., \& Ochana-Levin, T. (2004). Usage of and compliance with power tactics in routine 
versus nonroutine work settings. Journal of Business Psychology, 18, 385-402. doi:10.1023/B:JOBU. $0000016713.86935 .1 \mathrm{~b}$

Skakon, J., Nielsen, K., Borg, V., \& Guzman, J. (2010). Are leaders' well-being, behaviours and style associated with the affective well-being of their employees? A systematic review of three decades of research. Work \& Stress, 24, 107-139. doi:10.1080/ 02678373.2010 .495262

Snijders, T. A. B., \& Bosker, R. J. (1999). Multilevel analysis: An introduction to basic and advanced multilevel modelling. London: Sage.

Sonnentag, S. (2005). Burnout research: Adding an off-work and day-level perspective. Work \& Stress, 19, 271-275. doi: $10.1080 / 02678370500386473$

Talbot, R., Cooper, C., \& Barrow, S. (1992). Creativity and stress. Creativity and Innovation Management, 1, 183-193. doi:10.1111/caim.1992.1.issue-4

Tepper, B. J. (2000). Consequences of abusive supervision. Academy of Management Journal, 43, 178-190. doi: $10.2307 / 1556375$

Turner, J. C. (2005). Explaining the nature of power: A three process theory. European Journal of Social Psychology, 35, 1-22. doi:10.1002/(ISSN)1099-0992
Van Knippenberg, D., Lossie, N., \& Wilke, H. (1994). In-group prototypicality and persuasion: Determinants of heuristic and systematic message processing. British Journal of Social Psychology, 33, 289-300. doi:10.1111/bjso.1994.33. issue-3

Walster, E., Walster, G. W., \& Berscheid, E. (1978). Equity: Theory and research. Boston, MA: Allyn and Bacon.

Webster, D. M., \& Kruglanski, A. W. (1994). Individual differences in need for cognitive closure. Journal of Personality and Social Psychology, 67, 1049-1062. doi:10.1037/00223514.67.6.1049

World Health Organization. (2003). Work organization \& stress: Systematic problem approaches for employers, managers and trade union representatives. Geneva: Author. Retrieved from http://apps.who.int/iris/handle/10665/42625

Yerkes, R. M., \& Dodson, J. D. (1908). The relation of strength of stimulus to rapidity of habit-formation. Journal of Comparative Neurology and Psychology, 18, 459-482. doi:10.1002/(ISSN)1550-7149

Yukl, G., \& Falbe, C. M. (1991). Importance of different power sources in downward and lateral relations. Journal of Applied Psychology, 76, 416-423. doi:10.1037/00219010.76.3.416 